\title{
Assimilation of the Patient Rights Law and Code of Ethics into Israeli Physical Therapy Services
}

Tamar Jacob

Ariel University, tamar@ariel.ac.il

Ilana Zilberstein

Ariel University

Follow this and additional works at: https://nsuworks.nova.edu/ijahsp

Part of the Medicine and Health Sciences Commons

\section{Recommended Citation}

Jacob T, Zilberstein I. Assimilation of the Patient Rights Law and Code of Ethics into Israeli Physical Therapy Services. The Internet Journal of Allied Health Sciences and Practice. 2014 Apr 01;12(2), Article 7.

This Manuscript is brought to you for free and open access by the College of Health Care Sciences at NSUWorks. It has been accepted for inclusion in Internet Journal of Allied Health Sciences and Practice by an authorized editor of NSUWorks. For more information, please contact nsuworks@nova.edu. 


\title{
Assimilation of the Patient Rights Law and Code of Ethics into Israeli Physical Therapy Services
}

\begin{abstract}
The ethical conduct of physical therapists is usually based on intuition rather than on theoretical knowledge. This study aimed to examine to what degree rules of ethics anchored in the Patient Rights Law and in the Physical Therapy Code of Ethics in Israel have been assimilated in physical therapy (PT) services. A qualitative study based on personal semi structured interviews with national directors of PT services in Israel was conducted. The directors think that the ethical conduct of physical therapists is based mainly on intuition and on self-perceived ethics rather than on learned principles. In their opinion, the Patient Rights Law and the PT Code of Ethics, as well as the activity of the Ethics Committee of PT, have probably contributed to raising awareness of the need to promote the issue of ethics, but there are still no structured training programs on this topic in any of the Health Maintenance Organizations. (HMOs). Collaboration between the Ethics Committee of PT and representatives of the clinical field and of academe has the potential to advance the knowledge, thinking and discussion on ethics within all the community in all PT facilities. Part of this process is the assimilation of ethical rules in the daily practice of physical therapists.
\end{abstract}

\section{Author Bio(s)}

- Tamar Jacob, PhD, Physiotherapy Department, Ariel University, Israel.

- Ilana Zilberstein, PhD, Physiotherapy Department, Ariel University, Israel. 


\title{
1IVAHSP \\ The Internet Joumnal of Allied Health Sciences and Practice \\ Dedicated to allied health professional practice and education \\ http://ijahsp.nova.edu Vol. 12 No. 2 ISSN 1540-580X
}

\section{Assimilation of the Patient Rights Law and Code of Ethics into Israeli Physical Therapy Services}

\author{
Tamar Jacob, PhD. \\ llana Zilberstein, PhD. \\ Physiotherapy Department, Ariel University \\ Israel
}

\begin{abstract}
The ethical conduct of physical therapists is usually based on intuition rather than on theoretical knowledge. This study aimed to examine to what degree rules of ethics anchored in the Patient Rights Law and in the Physical Therapy Code of Ethics in Israel have been assimilated in physical therapy (PT) services. A qualitative study based on personal semi structured interviews with national directors of PT services in Israel was conducted. The directors think that the ethical conduct of physical therapists is based mainly on intuition and on self-perceived ethics rather than on learned principles. In their opinion, the Patient Rights Law and the PT Code of Ethics, as well as the activity of the Ethics Committee of PT, have probably contributed to raising awareness of the need to promote the issue of ethics, but there are still no structured training programs on this topic in any of the Health Maintenance Organizations. (HMOs). Collaboration between the Ethics Committee of PT and representatives of the clinical field and of academe has the potential to advance the knowledge, thinking and discussion on ethics within all the community in all PT facilities. Part of this process is the assimilation of ethical rules in the daily practice of physical therapists.
\end{abstract}

\section{INTRODUCTION}

The main questions being asked in Professional Ethics are: "How must one conduct oneself and what should one refrain from doing when working in a certain profession?"1,2 The ethics domains are usually divided into three main categories: the therapistpatient relationship, commitment to the profession and to colleagues, and the public role of the physical therapist as a member of society. ${ }^{3}$ Ethical issues usually arise as a result of ethical conflicts that appear at times within the profession or of the contradiction between professional commitments and commitments to people outside the profession. ${ }^{4,5} \mathrm{In}$ order to choose the most appropriate behavior and to justify one's decision, such situations require careful and critical judgment. 5,6 While healthcare professionals often encounter similar therapeutic situations there are also unique situations in each profession. Thus, ethical dilemmas that arise may be common to other professions or unique to a certain profession. ${ }^{7-9}$

The physical therapy (PT) profession is in a constant process of progress and development in developing new therapeutic approaches and techniques, in expanding fields of occupation and therapist authority and in research. In recent years, physical therapists have more judgment and authority to reach professional decisions. As therapists, they must make ethical decisions in the process of their clinical work, consciously and rationally. Therefore, their burden of responsibility is heavier and the ethical dilemmas involved in their practice are more complex than previously. 2,10

The unique ethical domains of the PT profession result from its role. For example, the duration of treatment is usually lengthy, therapists and patients are in close physical proximity, in most cases there is need for verbal communication between therapists and patients, and most treatments improve one's quality of life rather than saving lives. However, most of the PT professional ethos, similar to other healthcare professions, consists of care, commitment, and an empathic and sympathetic attitude to patients. ${ }^{11}$ 
Purtilo directed attention to unique ethical aspects of PT and recognized the need to identify ethical issues encountered by physical therapists and to define them. Since then, research has been conducted with the aim of identifying unique ethical domains of PT and ranking them by order of significance for the profession. $5,7,12,13,14,15$ All these studies have indicated that the most important ethical domain and the one that most occupies professionals is dealing with the therapist-patient relationship in all its aspects. The question is what affects the ethical conduct of physical therapists and to what degree does their formal training provide them with tools to cope with ethical dilemmas that arise throughout their work. ${ }^{16}$

Studies exploring the ethical conduct of physical therapists examined, among other things, respondents' level of theoretical knowledge in the field of ethics. ${ }^{9}$ These studies asked on what physical therapists base their ethical considerations when encountering an ethical dilemma. For example, a study conducted in Israel found that physical therapists usually conduct themselves intuitively based on their home education and various external influences rather than on theories, principles, or ethical rules. ${ }^{16}$ Furthermore, different physical therapists were found to perceive the concept of ethics and the entire subject of ethics differently. Similar findings were presented in a study conducted in Australia. ${ }^{17}$ In that study, one of the conclusions were that physical therapists take a narrative approach in which personal stories serve as the major conduit for analyzing an ethical problem and reaching a decision rather than a theoretical framework (such as laws or codes). This finding is logical based on the fact that physical therapists lack a theoretical foundation, and it is also compatible with research findings from the US and Canada. 18,19

In democratic countries ethical principles, as practical moral foundations, are usually manifested in the law as well. Israel does not yet have a wide constitutional foundation, however there are basic laws and other laws that reflect the character of the State of Israel as a liberal democratic state with ethical values. ${ }^{20}$ Therefore, professional ethical laws and codes include sections that express similar principles, and codes of ethics imbue these principles with meaning as appropriate for each profession. One of these laws is the Patient Rights Law 1996. ${ }^{21}$ The law is formulated in general terms for all healthcare professions and its purpose is to determine the rights of individuals who seek or receive medical care and to protect their honor and privacy. The law is based on values of human respect, respect for human autonomy and equality. Its main items relate to the right to receive proper medical care, to receive information about the identity of those caring for them, to ask for second opinion and to maintain their honor and privacy. (For more details see appendix 1).

One way of assimilating rules of ethical conduct among members of a specific profession is to construct a unique code of ethics. A professional code of ethics is a document that expresses the practical ideal conduct, which is a list of values and principles that provides a wide and stable foundation for justified decisions concerning proper professional conduct. 22,23 The code of ethics also serves as a yardstick for ethical judgment by defining the limitations of customary professional and ethical conduct. The code of ethics must serve as an educational tool for teaching professional ethics and be well known and implemented so that it can assist in reaching ethical decisions in real time. A code of ethics must be a "living document", i.e. it must be updated, expanded, and changed to fit shifts in the orientation and values of the organization and/or the professional community and society..$^{24,25}$

The PT Code of Ethics in Israel is similar to codes of ethics of PT organizations in other western countries and refers to the obligations of physical therapists as professionals. ${ }^{26}$ The section on physical therapists' obligations to their patients was written in the spirit of the Patient Rights Law. They are obliged to treat any person with respect and to maintain patients' rights, as well as acting according to the laws and procedures customary in Israel. In the field of healthcare, therapists should provide professional, responsible, and quality services based on customary standards and updated knowledge, act in the limits of their professional abilities and the knowledge at their disposal, and perform diagnostic and therapeutic procedures involving manual contact while maintaining patients' rights over their body and honor. In addition, physical therapists must provide patients with explanations of test findings and treatment programs and receive their consent for treatment.

In the public sphere, physical therapists are expected to promote and develop the profession through channels of therapeutic interventions, education, and research. Such activities may contribute to healthcare needs of the society and of the individual and to education and guidance of the future generation of physical therapists. In addition, it should provide the general public with information and explanations about the profession of PT and the work of the physical therapist.

In recent years an ethics committee has been established on behalf of the Israeli PT Society. Members of the committee are representatives of the Ministry of Health $(\mathrm{MOH})$, the Health Maintenance Organizations (HMOs), academe, and lately a physical therapist from the private sector was added as well. The committee puts a great deal of effort into assimilating ethical thought and conduct among physical therapists. For example, the committee organized a day-long seminar for senior directors of the PT services and heads of PT departments at the universities (March 2012) where tools for assimilating ethics in the various organizations were determined. The committee's activity is conducted in cooperation with all organizations responsible for PT

(c) The Internet Journal of Allied Health Sciences and Practice, 2014 
services in Israel and with the departments of PT in academic institutions. In addition to its activities promoting ethical thought and conduct, the committee can be consulted by physical therapists, clients, and others. The committee is also responsible for updating the code of ethics in accordance with the spirit of the times and evolvement of the profession in Israel and elsewhere.

Familiarity with the code of ethics and its assimilation promotes the profession and enhances its image as perceived by clients and by society in general. It is assumed that physical therapists should acquire knowledge of ethics and of decision making skills in order to cope better with ethical dilemmas. To date, knowledge of ethics acquired in basic professional training is fairly limited. ${ }^{15,16}$

Directors of PT services are responsible for promoting assimilation of the rules of ethics and of the code of ethics and equipping physical therapists with suitable tools for incorporating the Code of conduct and the Patient Rights Law as a basis for their ethical reasoning in practice. In addition, major ethical problems are usually addressed to them. This position enables them to be aware of ethical problems in practice. Therefore, they can serve as a good authority for describing actual assimilation of the principles of the Patient Rights Law and of the PT Code of Ethics and the values they represent among physical therapists working in the organizations they head. This study aims to examine the degree to which rules of ethics anchored in the Patient Rights Law and in the PT Code of Ethics are assimilated in Israeli PT services from the perspective of national service directors. The following questions were raised during the interview: 1. Are Israeli physical therapists familiar with the content of the Patient Rights Law and with the PT Code of Ethics. 2. What are the ways of assimilating the Patient Rights Law and the PT Code of Ethics in clinical settings? 3 . What are the future plans for assimilating the law and the code?

\section{METHODS}

A qualitative study was conducted using personal interviews, based on semi-structured open ended questions. Participants were all national directors of Israeli PT services. This method lets the meaning of ethics emerge from the interviewees rather than impose the researcher's definitions of variables on the participants. ${ }^{27,28}$ It was chosen because ethical behavior is not defined precisely and we wanted to hear the directors' perception of this topic. The study is part of a larger study of the assimilation of health related laws in PT services in Israel.

The study population consisted of 10 national directors from the various PT fields, including the head physical therapist at the $\mathrm{MOH}$, directors of PT services at the four major HMOs (all the directors of PT services at Israeli HMOs were replaced over the past two years, and therefore both the new and the recently retired directors were interviewed), the head advisor for PT at the Ministry of Social Affairs, and the (former) national counselor for PT at the Ministry of Education (MOE). Notably, the MOH functions both as a regulator and as an employer and thus the head of the PT department has two roles.

Initial contact with the directors was made in a telephone call from the principal investigator in which the purposes of the study were explained and invited them to be interviewed. Directors who needed the approval of their organization were asked to call back once permission was received. Finally, 9 out of 10 directors confirmed their participation. All interviewees signed an informed consent to participate in the study and consented to recording of the interview. The interviews were conducted by the principle investigator and a research assistant who also transcribed the text. The transcription was sent to the interviewees for their approval before data analysis. Interviewees whose identity was known within the physical therapist community gave special consent to use their statements. The research was approved by the Ethics Committee of Ariel University.

The interview included open ended questions about familiarity with the Patient Rights Law and the PT Code of Ethics, ways in which personnel are exposed to the Code of Ethics, , the training of personnel on ethical issues that arise, and coping with ethical problems (Appendix 2). The subjects included in the interviews were sent to two senior physical therapists with managerial experience for their comments and received their approval.

The text was analyzed by the principle investigator in the following stages. 1) The text underwent linguistic editing with the purpose of reducing repetitions and omitting irrelevant contents expressed in the interview. 2) Once all the interviews have been edited, the data was reviewed in order to identify common, recurrent, or emerged themes. ${ }^{29}$ This was done by looking if there are similar traits between respondents who present the same themes. ${ }^{29}$ At this stage, each interview was analyzed separately and select quotes were collected to support the analysis. 3) The interviews were merged by categories, concealing the names of interviewees and HMO's. 4) The text in each category underwent linguistic editing in order to present the results as clear as possible, without changing its content. That was done by reading the original transcription over again parallel to the editing process.

(C) The Internet Journal of Allied Health Sciences and Practice, 2014 


\section{RESULTS}

The interviewees' answers to the main studies questions cover also additional themes emerged from the interviews. The main themes relate to the present ethical behavior, to insufficient assimilation of ethical rules and to future steps.

The themes are presented in table 1 and described along the results section. In general, the directors are of the opinion that the large majority of physical therapists behave morally and ethically and follow the law intuitively. As evidence, complaints regarding ethics are very rare. Most of the complaints brought have to do with the availability of treatments, a problem associated with the system and not with the personal conduct of physical therapists.

According to the directors, physical therapists believe that they are doing their best from an ethical perspective and that most professionals are indeed morally inclined. One director said: "Most physical therapists cope well with ethical issues related to therapy. I have never been summoned to the ethics committee to explain unethical conduct of physical therapists." Yet, most of the directors expressed dissatisfaction with insufficient awareness of physical therapists concerning rules of ethics. Some of them think that privacy is not sufficiently maintained and that the significance of maintaining respect for patients has not been assimilated in some cases. For example "It's a disease of the entire medical field. For example, in hospital elevators there are announcements warning against speaking about patients, but you can often encounter doctors or physical therapists who ignore the sign and talk" or "... too many open conversations about patients are held in the staff room".

Table 1. Main themes emerged from the interviews.

\section{Themes related to present ethical behavior:}

1. Improved awareness of ethics in PT services in recent years.

2. The large majority of physical therapists behave morally and ethically.

3. The large majority of physical therapists follow the law intuitively.

\section{Themes related to insufficient assimilation of ethical rules:}

1. A gap between knowledge of the law and the code's principles and its assimilation in clinic.

2. Insufficient awareness of physical therapists to patient's right to maintain medical confidentiality.

3. Dealing with ethical issue is not prioritized at PT clinics.

4. The degree of assimilation of the Patient Rights Law and the PT code of ethics differs between HMOs.

\section{Themes related to future steps:}

1. A need to develop formal programs to assimilate ethical rules at all HMOs,

2. The importance to include ethics training at PT undergraduate curricula.

3. A need for collaboration between PT associations, PT departments at all health organizations and the academe in order to promote the assimilation of the Patient Rights Law and the PT code of ethics.

\section{Are Israeli physical therapists familiar with the content of the Patient Rights Law and the PT code of ethics?}

Most directors agree that awareness of ethics in PT services has improved recently and that the Patient Rights Law and the Code of Ethics have probably led to some behavioral change among therapists. However, they also agree that publicizing the Patient Rights Law and the PT Code of Ethics on the website and on bulletin boards at the entrance of PT facilities, as done today, is not enough, as was expressed by one director: "The Code of Ethics is hanging on the wall. I'm sure they read it, but in order for the words to receive their full meaning it is necessary to raise ethical issues for discussion at staff meetings". They assumed that the main points of the law and the code are known. Nonetheless, the directors were of the opinion that physical therapists are not sufficiently familiar with the law and the code and even stated that no guidance activity had been held to present it beyond hanging the poster. Examples given by directors: "The law is publicized in all facilities. The MOH requires this. 
In general people are familiar with it but we have not held any explanatory guidance activity on the Patient Rights Law." and also: "We haven't dealt with it. It's coming up more now. We spoke about it at the last conferences, but not enough."

According to the national counselor for PT at MOE, in PT services within the educational system, medical confidentiality is maintained outwardly but sometime there are problems with the dynamics of the discourse at staff meetings. According to her: "In recent years awareness of the issue has risen, parents' permission is sought before presenting children as a case study in external forums, photographing children, or including children in professional courses as clients. In addition, case descriptions are now confidential and concealed". and "in the past, particularly at pre-schools, it was customary to treat children in their underclothes. At present children appear for therapy in shorts or other suitable clothing, to make sure that they are treated with respect at any age. Another ethical problem arose was therapists tendency to judge parent and child conduct. She said: "Some of the staff believes that they know what is good for the child, and are angry at parents for not behaving according to their expectations. The staff must understand that children belong first and foremost to their parents and that the latter have the right to decide what is and isn't good for their children. They should learn to respect and accept this wholeheartedly". According to the counselor, in such cases, staff tendency is expressed in their manner of speech and in how they convey information.

Full satisfaction with the ethical conduct of physical therapists was evident in regard to those working in settings affiliated with the Ministry of Social Affairs. In the opinion of the PT advisor, "therapists in this system are very strict about maintaining medical confidentiality and privacy and failure to do so is perceived as a serious disciplinary offense". She explained that this approach is based on the Welfare Law (Care for Mentally Retarded, ${ }^{27}$ enacted about 30 years. ${ }^{19}$ For example: "Photographs of residents may not be presented without receiving the permission of the family or the legal guardian and without the permission of the facility".

\section{What are the ways of assimilating the Patient Rights Law and the PT Code of Ethics?}

The directors agree that the rules of ethics must be refreshed occasionally, as stated by one interviewee: "It is always necessary to remain alert because the tendency is to lose sensitivity. You stop being sensitive and at some stage it can become dangerous." In their opinion, in order to assimilate the spirit and the rules of the law and code it is necessary to be more active, for example to raise ethical issues for discussion at staff meetings. The common trend today is to put the topic aside and discuss it only when there is an irregular incident or when a complaint is made. One director claimed that?: "The topic is not dealt with separately due to other priorities". They are aware of the difficulties in assimilating these topics among the staff as one of the interviewees said: "Dealing with ethics is even harder today because you have to talk about a subject that people think they are familiar with although they are not. Sometimes it concerns workers' daily conduct at work. This is the reason for the difficulty involved in teaching older people who have been working for 20-30 years about ethics. I think that the process should begin in basic academic studies."

Most directors reported that there is a mechanism for assimilating the main points of the law in their organization but they doubt its efficiency. In one of the HMOs there is a project to enhance patients' rights that includes the department of PT. The director stated that "The purpose of the project is to reflect to patients their rights as patients and clients. The reflection should be available and accessible, with consideration for clients' cultural background". Directors of the facilities receive updates on the project. In some places attempts were made to convey the main points of the law through one-time lectures or talks at staff meetings but not in a systematic and orderly manner that would include all settings in that organization. The head physical therapist at the $\mathrm{MOH}$ explained that with the recent enactment of the Law Regulating the Practice of Healthcare Professions $(2008)^{30}$ a new direction for assimilating the Patients' Right Law has emerged. According to this law, physical therapists must take government exams in order to receive a diploma. The exams, include questions on the law, will probably contribute to raising awareness of the subject among new graduates.

One of the recently retired directors mentioned that about two decades ago, a multi-disciplinary committee was established and formulated the first version of the Israeli PT Code of Ethics. The PT organization held guidance and assimilating activities strongly supported by some of the HMOs. These activities fell through and the subject was neglected for many years. According to her, today there is an awakening in this field and in addition to publicity on the internet and on bulletin boards some of the organizations have taken additional steps. For example, in one HMO "there is a file intended for new workers, including all the contents they must receive when beginning work. The file includes, among other things, the Code of Ethics, the methods of the organization, and the vision of PT." In addition, in that HMO, role modeling by colleagues is stressed.

Another method is by using regular client feedback. In one HMO, the clients of each facility are surveyed regularly for their satisfaction with the service, including ethical aspects of the service. Satisfaction standards reported by patients were determined. Facilities are graded and if the assessment is low a meeting is held with the staff and the problems that arise are reflected. In one of the HMOs, complaints on a systemic level are referred to the Customer Service Commissioner and the legal

(C) The Internet Journal of Allied Health Sciences and Practice, 2014 
department. Work processes are well structured. Physical therapists must report incidents on a special form to their facility director or directly to the complaint coordinator. The PT director at this HMO claims that: "Since the procedures were set there has been a rise in the number of reports but the assumption is that there is no change in the number of irregular incidents, rather only in the number of reports". She added that in fact, a norm of learning from complaints and reaching conclusions in order to prevent future complaints has been assimilated.

The directors agree that it is important that the initial exposure to ethics take place in academe when studying for the bachelor's degree. In their opinion, at this stage students should be presented not only with the sections of the code but also with examples of ethical dilemmas from the field in order to receive actual clinical significance.

\section{What is the future plan for assimilating the law and the code?}

The major HMOs are currently preparing to design new programs to promote ethical issues. In other settings there is an awareness of the significance of ethics but nothing has been done about it yet. The following ideas have been proposed: designing a computer program that will be compulsory for all physical therapists, raising ethical dilemmas at staff meetings (for example, discussing treatments for dying patients), training "ethics monitors" (there is a plan to send more people to a course operated by the Ethics Committee for PT). The purpose is to assimilate ethical conduct and expand knowledge of all patient rights at PT facilities and services in the community and in hospitals. Ethics monitors will be equipped with a kit called "ethical conduct". They will be responsible for assimilating the subject in their area. Ethics trustees will be equipped with a kit called "ethical conduct". They will be responsible for assimilating the subject in their area.

One of the HMOs has already taken a first step toward carrying out this idea. A trustee of ethics has been selected to lead the subject, with regional trustees subject to him. The intention is to organize a training course on ethics on behalf of the HMOs and to design a work process for assimilating the subject. The first area to be chosen for analysis of the process of assimilating the Code of Ethics is pelvic floor rehabilitation. The purpose is to see how a focused code of ethics can be built in a small group and then assimilated in larger groups. Another suggestion was to hold discussions of case studies and day-long seminars on ethical dilemmas in the field. In the $\mathrm{MOH}$, a disciplinary committee for disciplinary problems and unethical conduct of professionals is planned, following the directives of the Law Regulating the Practice of Healthcare Professions. ${ }^{30}$

\section{DISCUSSION}

Service directors think that Israeli physical therapists are familiar, to some extent, with the Patient Rights Law and with the PT Code of Ethics, but behave morally and ethically by intuition rather than by ethical rules. They understand that there is a gap between knowledge of the law and the code's principles and its assimilation in clinic. To date, the most common ways to assimilate the law and the code are by publicizing them on the web and hanging posters on bulletin boards at the entrance of PT facilities. The directors agree that recently there is an increased awareness of the importance of assimilating the patients' rights, and ethical rules in clinics. Yet, there are not formal programs to promote this topic at any of the HMOs. Among the suggested future plans for assimilating the law and the code, were designing a computer program, raising ethical dilemmas at staff meetings and including ethics studies in undergraduate curricula.

\section{Physical therapists familiarity with the Patient Rights Law and with the PT Code of Ethics}

All directors believe that most of the physical therapists are familiar with the Patient Rights Law and with the PT Code of Ethics to some extent. However, in their opinion the ethical conduct of physical therapists derives mainly from intuition and self-perceived ethics and not from learning principles or laws. This notion is supported by studies conducted in Israel and in other countries. ${ }^{16-19}$ Several factors can explain this situation. The directors agree that publishing the law or the code of Ethics on the web or on bulletin boards is not an efficient way to assimilate their content and massages in clinical practice. Furthermore, the ethical issue is not at the leading priorities of PT departments and of physical therapists themselves to date. They also think that the present undergraduate curricula at all universities do not provide enough time for ethical issues. Therefore, the young graduates are not properly trained to deal with ethical dilemmas in clinics.

\section{Ways of assimilating the Patient Rights Law and the PT Code of Ethics}

The directors agree on the significance of assimilating the Patient Rights Law and the PT Code of Ethics and on the need to hold training in order to achieve this goal. For many years talk was heard of the need to deal with ethics but this was not done. Most of the activities for promotion of ethics are now performed in public facilities and ways of reaching the large group of physical therapists who are self-employed or work in privately owned facilities or clinics are sought. This is only the beginning and there is a lot of work to be done. 
Most directors agree that in order to raise awareness of the ethical issues they must be emphasized occasionally, otherwise there is a tendency to take them lightly. However, most of the directors are aware of the difficulties involved in dealing with ethics as it is necessary to talk with workers who think that they are well-acquainted with the subject although in fact their knowledge is limited.

One example is the need to constantly maintain patients' privacy and autonomy. At a recent course for training ethics trustees, held on behalf of the Ethics Committee and operated by three of its members (December 2012), thirty representatives from all universities and clinical PT settings were trained for this role. In addition, the committee distributed a position paper on the "use of photography and information about patients while maintaining their confidentiality and privacy." Notably, this course took place about three months after the end of interviews with the directors. Thus, there are first signs of assimilation programs but there are still no programs in any of the HMO's for structured training on ethics. It can be assumed that the Patient Rights Law and the PT Code of Ethics, together with the activities of the Ethics Committee for Physical Therapy, have contributed to raising directors' awareness of the need to promote the subject of ethics in a structured manner.

Another point that arose in the interviews was the importance of ethics training of students during their studies as was suggested previously. ${ }^{31}$ Physical therapy students often practice treatments on each other throughout their training, in an open social atmosphere, where the "therapists" and the "patients" have known each other for some time and the sensitivity to patients' privacy is low. Later on, as physical therapists, they usually work in open spaces characteristic of PT facilities, where they come into constant physical contact with patients. This continuity might hamper their sensitivity to the requirement of maintaining real patients' privacy.

A study conducted on the ethical conduct of PT students in Israel reported proper conduct as manifested by their willingness to report therapist misconduct to protect patients' interests. ${ }^{32}$ Based on the personal knowledge of the researchers regarding study programs in PT (the principal author headed one of the departments and the co-author taught the subject), very little of the curriculum is devoted to ethics. A similar attitude to the significance of training PT and occupational therapy students in ethics and a proposal for a training program on the subject were suggested by a team of researchers from the University of Texas in the US, ${ }^{33}$ and in Australia. ${ }^{34}$ Nonetheless, as stated by some of the directors, the ethical domain must be re-stressed over time, as part of regular practice, and therefore in any case basic studies are not sufficient in order to assimilate the rules of ethics in clinical practice.

The identity of the HMO's was masked in this study due to ethical considerations, yet, it is interesting to point to some differences between them in general. The interviews exposed large difference between PT services at the various HMO's regarding the assimilation of rules of ethics. The large HMOs are already taking operative steps to assimilate the rules of ethics and they are in a process of designing programs to promote it. The small HMOs have not yet begun a process of assimilation although service directors are aware of its significance. The differences probably stem from differences in directors' priorities due to the organizational conditions at their PT departments.

Private PT services seem to use only the intuitive approach of physical therapists and there is currently no agency leading assimilation processes in the ethical field. Recently a member of the private sector was added to the Ethics Committee, but in practice, since there is no organization that unites all independently employed physical therapists, this member does not speak for his colleagues. However, the PT Code of Ethics obliges all licensed professionals, even if they are self-employed. Thus, it can be assumed that activities initiated by the PT department of the $\mathrm{MOH}$ could contribute to this system as well. A similar conclusion was reached by researchers in regard to the ethics of Danish physical therapists. ${ }^{15}$ The renewed activities of the Ethics Committee for PT and the opinions expressed by service directors show that the subject is on the agenda not only of the HMOs rather also of PT associations.

Finally, most directors mentioned future plans for assimilating ethical rules in clinical practice. These plans may be an evidence for the increased attention to ethical issues lately.

\section{STUDY LIMITATIONS}

Data are based on interviews with national service directors. Directors in the field or the patients themselves may see the subject differently. There is no representative body of the private sector and therefore no representative of this sector could be interviewed. Finally, data analysis was performed by the principle investigator. May be, an analysis by another person could produce different perspectives.

(C) The Internet Journal of Allied Health Sciences and Practice, 2014 


\section{CONCLUSION}

Awareness to the importance of assimilating the ethical principles, derived from the Patients' right Law and the PT Code of Ethics, in PT clinics has increased during the last years. Yet, there is a gap between those principles and therapists' ethical behavior. It is suggested that specific programs for assimilating the ethical principles should be developed. In addition, Collaboration between the Ethics Committee of PT and representatives of the clinical field and of academe has the potential to promote the assimilation of ethical codes within the various clinical organizations. In order to generate assimilation of ethical codes in the daily practice of physical therapists this issue must be constantly emphasized. Future study should evaluate the contribution of such programs to the ethical conduct of physical therapists.

\section{REFERENCES}

1. Kucuradi I. Introduction: Philosophical Ethics and Professional Ethics. In Kucurady, I. (Ed.), Ethics of the Professions: Medicine, business, media, law (pp.1-8). 1999. Berlin: Springer.

2. Swisher LL. A retrospective analysis of ethics knowledge in physical therapy (1970-2000). Phys Ther. 2002;82(7):692-706. [PMID 12088466]

3. Chadwick R. Professional ethics. In: De Stexhe G. Verstraeten J. eds. Matter of Breath, Foundation for Professional Ethics. Leuven: Peeters 2000:47-56.

4. Beauchamp T, Childress JT. Principles of Biomedical Ethics. New York: Oxford University Press, 1994.

5. Geddes EL, Finch E, Larin H. Ethical Issues Relevant to Physical Therapy. Hamilton, ON, Canada: McMaster University, School of Rehabilitation Science, 1999.

6. Purtillo R. Ethical Dimensions in the Health Professions (4th ed.). Philadelphia: WB Saunders, 2005.

7. Guccione AA. Ethical issues in physical therapy practice: a survey of physical therapists in New England. Phys Ther.1980;60(10):1264-72. [PMID 7443788]

8. Delany CM, Edwards I, Jensen GM, Skinner E. Closing the gap between ethics knowledge and practice through active engagement: an applied model of physical therapy ethics. Phys Ther. 2010;90(7):1068-78. [PMID 20448105]

9. Carpenter $C$, Richardson B. Ethics knowledge in physical therapy: a narrative review of the literature since 2000. Physical Therapy Reviews. 2008;13(5):366-74.

10. Jensen GM, Gwyer J, Shepard KF, et al. Expert practice in physical therapy. Phys Ther. 2000;80(1):28-43, discussion 4452. [PMID 10623958]

11. Stiller C. Exploring the ethos of the physical therapy profession in the United States: social, cultural and historical influences and their relationship to education. J Phys Ther Educ. 2000;14(3):7-15.

12. Purtilo RB. Ethics teaching in allied health fields. Hastings Cent. Rep. 1978;8(2):14-6.

13. Purtilo RB. Understanding ethical issues: the physical therapist as ethicist. Phys Ther. 1974;54(3):239-43. [PMID 4460027]

14. Triezenberg HL. Examining the moral role of physical therapists. In: Purtilo R, Jensen GM, Royeen CB, eds. Educating for Moral Action: A Sourcebook in Health and Rehabilitation Ethics. Philadelphia: F.A. Davis Company 2005: 75-85.

15. Praestegaard J, Gard G. Ethical issues in physical therapy - reflected from the perspective of physical therapists in private practice. Physio Theory Pract. 2013;29(2):96-112. [PMID 22765019]

16. Zilberstein I. Identifying and analyzing ethical issues and studying ethical reasoning in physical therapy in Israel. Thesis submitted for the degree of Doctor of Philosophy. University of Haifa, Graduate Studies Authority. November 2009.

17. Edwards I, Mayer AB, Jones M. Ethical reasoning as a clinical-reasoning strategy in physical therapy. Physiotherapy. 2005;91:229-36.

18. Carpenter C. Dilemmas of practice as experienced by physical therapists in rehabilitation settings. Physiotherapy Canada. 2005;57(01):63-76.

19. Finch $\mathrm{E}$, Geddes $\mathrm{E}$, Larin $\mathrm{H}$. Ethically-based clinical decision-making in physical therapy: process and issues. Physio Ther Theor Prac. 2005;21(3):147-62. [PMID 16389696]

20. Gross ML. Autonomy and paternalism in communitarian society: Patient rights in Israel. Hastings Cent Rep. 1999;29(4):1320. [PMID 10451834]

21. Patient Rights Law. Jerusalem: Knesset 1996. [Hebrew]

22. Gabard D, Martin M. Physical Therapy Ethics. Philadelphia: F.A. Davis Company, 2003.

23. Kasher A. Professional ethics. In: Sheffler G. et al. eds. Ethics in Psychology. Jerusalem: Magness Press. 2003:15-29. [Hebrew]

24. Kohen D. Codes of conduct. In: Koehn D. The Ground of Professional Ethics. Routledge. London and New-York. 1994:15467.

25. Swisher LL, Hiller P, APTA Task Force to Revise the Core Ethics Documents. The revised APTA code of ethics for the physical therapist and standards of ethical conduct for the physical therapist assistant: theory, purpose, process, and significance. Phys Ther 2010;90(5):803-24. doi: 10.2522/ptj.20090373. [PMID 20223946] 
26. The Code of Ethics of Physical therapy in Israel. The Israeli Physical therapy Society.year? [Hebrew] Available from: http://www.ipts.org.il/?CategorylD=189\&ArticlelD=119

27. Sofar S. Qualitative research methods. Int J Qual Health Care. 2002;14(4): 329-6.

28. Britten N. Qualitative interviews in medical research. BMJ. 1995 July 22;311(6999):251-3. [PMID 7627048]

29. Braun V, Clark V. Using thematic analysis in psychology. Qual Res Psychol. 2006;3:77-101.

30. Law Regulating the Practice of Healthcare Professions. Book of Laws 2172. Jerusalem: Knesset 2008. [Hebrew]

31. Triezenberg $\mathrm{H}$, Davis $\mathrm{C}$. Beyond the code of ethics: educating physical therapists for their role as moral agents. Journal of Physical Therapy Education. 2000;14(3): 48-58.

32. Mansbach A, Bachner YG, Melzer I. Physical therapy students' willingness to report misconduct to protect the patient's interests. J Med Ethics. 2010;36(12):802-5. [PMID 20935313]

33. Lattanzi JB, Pechak C. A conceptual framework for international service-learning course planning: promoting a foundation for ethical practice in the physical therapy and occupational therapy professions. J Allied Health. 2011;40(2):103-9. [PMID 21695371]

34. Edwards I, Kessel $\mathrm{G}$ van, Jones $\mathrm{M}$, et al. The development of moral judgment and organization of ethical knowledge in final year physical therapy students. Phys Ther Rev 2012;7(3):157-66. 